2 Research Square
Preprints are preliminary reports that have not undergone peer review.

They should not be considered conclusive, used to inform clinical practice, or referenced by the media as validated information.

\title{
The Relationship Between Gross Motor Function,Manual Ability, and Cognitive Function With Quality of Life in Children with Cerebral Palsy
}

Mehdi Rasafiani ( $\nabla$ mrassafiani@yahoo.com)

Kuwait University, Kuwait, Occupational Therapy Department, Faculty of Allied Health Sciences

zahra Nobakht

Pediatric Neurorehabilitation Research Center, University of Social Welfare and Rehabilitation Sciences, Tehran, Iran

farin soleimani

Pediatric Neurorehabilitation Research Center, University of Social Welfare and Rehabilitation Sciences, Tehran, Iran

Nazila Akbarfahimi

University of Social Welfare and Rehabilitation Sciences

Roshanak Vameghi

Pediatric Neurorehabilitation Research Center, University of Social Welfare and Rehabilitation Sciences, Tehran, Iran

\section{Research Article}

Keywords: Quality of life, Function, Cerebral palsy, Child, Manual ability, Gross motor, Cognition

Posted Date: April 20th, 2021

DOI: https://doi.org/10.21203/rs.3.rs-418127/v1

License: (c) (i) This work is licensed under a Creative Commons Attribution 4.0 International License. Read Full License 


\section{Abstract}

Background:Cerebral palsy (CP) is the most common type of permanent movement and posturedisorder in childrenleading to contractures, deformities, and activity limitations. Quality of life is considered as an outcome variable to evaluate the effectiveness of interventions for children with CP. Therefore, we aimed to examine the relationship between quality of life and gross motor function,manual ability, and cognitivefunction inchildren with CP.

Methods:200children with CP aged 4-12 years participated in this study through convenient sampling. Then, their quality of life, gross motor ability, hand function, and cognitive level were assessed using Cerebral Palsy Quality of Life Questionnaire (CPQOL), Gross Motor Function Classification System scale, Manual abilities Classification System Scales and SPARCLE (Study of Participation of Children with Cerebral Palsy Living in Europe) scale, respectively.

Results: The results demonstrated that only the functional domain of the CPQOL was significantly correlated withthe manual ability and cognitive level in these children ( $P=0.001, P=0.001$ respectively).

Conclusions:A child with CP with poor performance has the potential to report a poorQOL. This needs more evidence for elaboration.

\section{Introduction}

Cerebral palsy (CP) is one of the most common movements and postural disorders in childhood that occurs because of a lesion in the developing brain(1). These children may experience a wide range of movement, postural, coordination, sensory, and cognitive disorders throughout their lives(2). Various treatment and rehabilitation interventions are performed to maximize the performance of these children $(3,4)$. Many efforts have been made to investigate the effect of these interventions on children with CP byemploying appropriate outcome measures. In recent years, quality of life (QOL), as a manifestation of health and well-being, has been proposed as an outcome measure for evaluating the effectiveness of interventions(5). In the International Classification of Functioning (ICF), QOLhas been proposed as the ultimate goal of interventions(6). QOL can also be considered as a predictor of a child's health status(7).

According to the definition of the World Health Organization, QOLis an individual's understanding of his or her situation and circumstances in life, which is based on their culture, value system, goals, expectations, standards, and priorities. Therefore, QOL is completely individualized and subjective and is based on people's understanding of different aspects of their lives $(8,9)$. Although QOL has a multidimensional structure, many researchers agree that it is equal to person's performance or ishighly dependent on their performance(10).Studies showed impairedQOL in children with CP. This degree of impairment is associated with the level of independence in daily activities, mobility, clinical limitations, and social interactions (11). Shelley and colleagues(12)examined the relationship between the QOL of children with $\mathrm{CP}$ and their level of performance. In their study, the CPQOL questionnaire was used to evaluate the QOL of children with CP, and Gross Motor Function Classification System (GMFCS) was used to evaluate their level of gross motor function.A significant relationship was found between the subscales of the QOL and gross motor function. However, this association was more related to thephysical subscalethan the psychosocial subscales. The relationship between performance and QOL is not limited to walking performance and a positive relationship between physical activity and QOL has also been reported(11).

Park and co-workers (13)usedpath analysisto assess the relationship betweenstrength, spasticity, gross motor function, and QOL on 62 children with spastic $\mathrm{CP}$. There wasa significant and direct relationship between spasticity, strength, and gross motor function, and between gross motor function and health-related QOL, as well asbetween strength and children's QOL. In another study, Kolmanand colleagues(7) examined the predictors of health and QOL. They foundthat factors related to comfort, emotions, communication, and social interactions predicted QOL more than mobility and self-care. Maher and co-workers(14)also reported that physical activity significantly predicted the quality of physical and social life. However, in a systematic review of studies on the QOL of children and adolescents with CP in the middle- and low-income countries, it was reported that the physical subscale of QOL of children with CP washighly affected, and this physical subscale wasstrongly correlated with motor function(15). However, these children have a high QOL in the psychosocial subscale even if they have low performance(12).

It seems that gross motor function and manual and cognitive ability could predict the QOL of children with CP. Therefore, we aimed to investigate the relationship between performance of children with $\mathrm{CP}$ in terms of gross motor function, manual ability, and cognitive function with theirQOL.

\section{Methods}

In thiscross-sectional studywith non-probability sampling, 200 children with CP were enrolled fromeight rehabilitation centers and three schools for children with physical disabilities. We included children aged 4-12 years diagnosed with CP according to their medical records or their therapists' report, whose parents were literate andagreed with their participation. Children were classified topographically and physiologically according to the Surveillance of Cerebral Palsy in Europe (SCPE)(16).

\section{Tools and Measures}

The data for this study were collected using asocio-demographic characteristics questionnaire,the Persian version of the CPQOL-parent, GMFCS,Manual Ability Classification System (MACS), and the SPARCLE cognitive level estimation form.

The socio-demographic questionnaire includes 46 questions divided intofour sections: questions related to the child, the parents, the child's caregiver, and the child's health status.

The CPQOL-parent versionmeasures condition-specific QOL and is completed by the parents. This questionnairehas 66 items and is appropriate to assess the QOL of children with CP aged 4-12 years. The answer to each question is divided into a 9-pointLikertscale, which the parent either selectsor draws a line around 
$(17,18)$.CPQOL has sevensubscales, including(1) social well-being and acceptance; (2) functioning; (3) participation and physical health; $(4)$ emotional wellbeing; (5) pain and impact of disability; (6) access to services; and (7) family health. The Persian version of the CPQOL-parent version questionnaire was validated according to the protocol provided by the developers (19), and had acceptable reliability (ICC $=0.47-0.84)$ and the subscales had appropriate internal consistency $(\mathrm{a}=0.61-0.87)(19)$.

Gross motor function was assessed according to the GFMCS and based on spontaneous gross movement such as the child's head control, sitting, standing, and transferring(20). In this system, the gross motor function of children with CP is classified into five levels. In level one, children have the most, and in level five, children have the least independent motor function. This scale has acceptable validity and reliability $(20,21)$.

The MACS assesseschildren's manual ability based on how their hands are used to control objects in everyday life(22). This system is defined in five levels similar to the GFMCS. Children in level one have the highest manual ability function, and children in Level five have the least control over the objects. MACS has been validated in Persian and has an acceptable level of validity and reliability (23).

Cognitive function in children with CP was estimated and classified into three levels including: $>70,70-50,<50$. This classification was prepared and used by SPARCLEin Europe(24). Parents with children with CP are asked to answer four questions. Then, based on their responses, the children's cognitive level is identified.

\section{Procedures}

Following the recruitment of the participants, the aims and steps of completing the questionnaireswere explained to them. Then, upon their willingness,written consent was obtainedfrom the parents. In the next steps, the questionnaires of the study were completed according to the following order. First, CPQOL and socio-demographicquestionnaireswere completed consecutively by the parents. Then, the children's GFMCS, MACS, and level of cognition were identified by an assessor (three occupational therapists) by interviewing the parents. On average, the whole process took about 60 minutes. This study was approved by the Ethical Committee of the University of Social Welfare and Rehabilitation Sciences(ID: 801/4/88/58).

\section{Data analysis}

Data were analyzed using SPSS software, version 19. Descriptive statistics were used to determine the characteristics of the participants. Linear regression was used to investigate the relationship between the subscalesof CPQOL and children's functions, including gross motor function, manual ability, and cognitive function.

\section{Results}

The mean \pm SD age of the 200 children participating in this study was $7.7 \pm 2.40$ years. The distribution of various levels of manual ability function was almost close to each other in five levels according to MACS. Levels four and three hadthe highest percentage with $23 \%$ and $20 \%$, respectively, and the other levels were $19 \%$ each. The distribution of gross motor function according to the GFMCS was different fromMACS. Levels four and two were the highest with $30.5 \%$, and $24.5 \%$ respectively. The lowest percentage was at level one with $11 \%$ (Table 1 ). 
Table 1

Demographic characteristics of children with $\mathrm{CP}$

\begin{tabular}{|c|c|c|}
\hline & Number & Percent \\
\hline \multicolumn{3}{|l|}{ Sex: } \\
\hline Female & 97 & 48.5 \\
\hline Male & 103 & 51.5 \\
\hline \multicolumn{3}{|l|}{ Cerebral Palsy Type: } \\
\hline Spastic (Unilateral) & 36 & 18.0 \\
\hline Spastic (Bilateral) & 125 & 62.5 \\
\hline Ataxic & 10 & 5.0 \\
\hline Dyskinetic & 14 & 7.0 \\
\hline Not Classified & 15 & 7.5 \\
\hline \multicolumn{3}{|c|}{ Manual Ability Classification System (MACS): } \\
\hline Level 1 & 38 & 19.0 \\
\hline Level 2 & 38 & 19.0 \\
\hline Level 3 & 40 & 20.0 \\
\hline Level 4 & 46 & 23.0 \\
\hline Level 5 & 38 & 19.0 \\
\hline \multicolumn{3}{|c|}{ Gross Motor Function Classification System (GMFCS): } \\
\hline Level 1 & 22 & 11.0 \\
\hline Level 2 & 49 & 24.5 \\
\hline Level 3 & 31 & 15.5 \\
\hline Level 4 & 61 & 30.5 \\
\hline Level 5 & 37 & 18.5 \\
\hline \multicolumn{3}{|l|}{ Cognitive function: } \\
\hline $50>$ & 36 & 18.0 \\
\hline $50-70$ & 46 & 23.0 \\
\hline $70<$ & 118 & 59.0 \\
\hline
\end{tabular}

Using linear regression, therelationship between CPQOL subscales and gross motor function did not show a statistically significant difference in any of the subscales.However, this relationship with the functioning subscale was close to a significant level $(P=0.071)($ Table 2$)$. Because of the similarity of the scale of variables with respect to non-standardized coefficients $B$, the most effective relationships were obtained with the subscales of functioning and participation and physical health. Negative relationships indicate an inverse relationship between severity of disability and QOL. 
Table 2

Linear regression analysis ofthe relationship between CPQOL subscales and the children'sgross motor function, manual ability and cognitive fun

\begin{tabular}{|c|c|c|c|c|c|c|c|c|c|c|c|c|c|c|}
\hline & & \multicolumn{5}{|c|}{$\begin{array}{l}\text { Gross Motor Function Classification System } \\
\text { (GMFCS) }\end{array}$} & \multicolumn{4}{|c|}{$\begin{array}{l}\text { Manual Ability Classification System } \\
\text { (MACS) }\end{array}$} & \multicolumn{3}{|c|}{ Cognitive function } & \\
\hline \multirow{2}{*}{\multicolumn{2}{|c|}{ Model }} & \multicolumn{2}{|c|}{$\begin{array}{l}\text { Non- } \\
\text { standardized } \\
\text { coefficients }\end{array}$} & \multirow{2}{*}{$\begin{array}{l}\text { Standardized } \\
\text { coefficients }\end{array}$} & \multirow[t]{2}{*}{$\mathrm{t}$} & \multirow[t]{2}{*}{ Sig. } & \multicolumn{2}{|c|}{$\begin{array}{l}\text { Non- } \\
\text { standardized } \\
\text { coefficients }\end{array}$} & \multirow{2}{*}{ 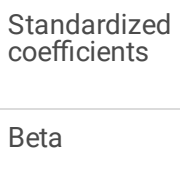 } & \multirow[t]{2}{*}{$\mathrm{t}$} & \multirow[t]{2}{*}{ Sig. } & \multicolumn{2}{|c|}{$\begin{array}{l}\text { Non- } \\
\text { standardized } \\
\text { coefficients }\end{array}$} & \multirow{2}{*}{$\begin{array}{l}\text { Standardized } \\
\text { coefficients } \\
\text { Beta }\end{array}$} \\
\hline & & B & $\begin{array}{l}\text { Std. } \\
\text { Error }\end{array}$ & & & & B & $\begin{array}{l}\text { Std. } \\
\text { Error }\end{array}$ & & & & B & $\begin{array}{l}\text { Std. } \\
\text { Error }\end{array}$ & \\
\hline \multirow[t]{8}{*}{1} & Constant & 5.297 & .593 & & 8.932 & .000 & 5.919 & .617 & & 9.588 & .000 & .841 & .338 & \\
\hline & $\begin{array}{l}\text { Social well- } \\
\text { being and } \\
\text { acceptance: }\end{array}$ & .000 & .008 & -.002 & -.017 & .987 & -.006 & .009 & -.061 & -.691 & .490 & .007 & .005 & .131 \\
\hline & Functioning: & -.017 & .009 & -.189 & -1.815 & .071 & -.041 & .010 & -.427 & -4.214 & .000 & .018 & .005 & .328 \\
\hline & $\begin{array}{l}\text { Participation } \\
\text { and physical } \\
\text { health: }\end{array}$ & -.013 & .009 & -.163 & -1.459 & .146 & .006 & .010 & .066 & .606 & .545 & -.005 & .005 & -.112 \\
\hline & $\begin{array}{l}\text { Emotional } \\
\text { well-being: }\end{array}$ & .005 & .008 & .064 & .616 & .538 & .001 & .009 & .016 & .155 & .877 & .006 & .005 & .127 \\
\hline & $\begin{array}{l}\text { Access to } \\
\text { services: }\end{array}$ & -.004 & .005 & -.057 & -.697 & .487 & .004 & .005 & .063 & .780 & .436 & -.004 & .003 & -.110 \\
\hline & $\begin{array}{l}\text { Pain and } \\
\text { impact of } \\
\text { disability: }\end{array}$ & -.001 & .005 & -.019 & -.262 & .794 & -.007 & .005 & -.102 & -1.455 & .147 & .000 & .003 & -.022 \\
\hline & $\begin{array}{l}\text { Family } \\
\text { health: }\end{array}$ & -.005 & .004 & -.103 & -1.212 & .227 & -.005 & .004 & -.098 & -1.181 & .239 & .003 & .002 & .103 \\
\hline
\end{tabular}

The results of linear regression regardingthe relationship between the CPQOLsubscales and the children's manual ability were not statistically significant except for the functioningsubscale $(\mathrm{P}<0.001)$ (Table 2$)$.

The relationship between CPQOL subscales and the children's cognitive level showed a statistically significant relationship only with the functioning subscale $(P<0.05)$ (Table 2). The relationship with other subscales was not statistically significant.

\section{Discussions}

In this study, the relationship between CPQOLsubscales and children with CP's functions (gross motor function, manual ability, and cognitive level) were investigated.The main question of this study was: do children with a high level of function (i.e., gross motor, manual ability, and cognitive level) have a higher quality of life?According to the result of this study, the relationship between CPQOL subscales and gross motor function did not show a statistically significant in any of the subscales. Also,the relationship between the CPQOLsubscales and the children's manual ability wasnot statistically significant except for the functioningsubscale.The relationship between CPQOL subscales and the children's cognitive level showed a statistically significant relationship only with the functioning subscale.

In previous studies, it has been concluded that despite the relationship between performance and physical subscales ofQOL, there is no relationship between performance and psychosocial subscales ofQOLor this relationship is weak. It should be noted that in these studies, questionnaires used assessed the activities that the child can do more than the general well-being of children. In other words, they weremore related to performance than well-being(25, 26). Wellbeing is a broader term than performance and is a more appropriate term to describe health. Well-being includes the presence of positive emotions and moods, the absence of negative emotions, satisfaction with life, fulfillment, and positive functioning. In our study, we use CPQOL questionnaire that evaluates well-being along with functioning and participation. Shelley and colleagues(12)investigated the QOL of children with CP based on CPQOL as well asits relationship with gross motor function. We used this questionnaire not only for gross motor function but for manual ability and cognitive function as well. We found thatnot only the relationship between QOL subscale of functioning and gross motor function was closed to a significant level, but this relationship was also significant forthe child's manual ability and cognitive level. This is a confirmation of previous studies, adding that regarding performance, not only gross motor performance but also the manual ability and cognitive level should be considered. In a study on children who were ambulated,Omuraand coworkers(27)founda significant relationship between walking abilities and the physical subscale of CPQOL. They also reported that there wasa positive correlation between physical function, gait function, and a child's level of communication with physical subscales of QOL. However, this study was performed on children who were able to walk.

Delicate motor function, including speed and mastery of the upper limbs and visual-motor control, were named as the most important motor factors affecting the QOLof children with CP in a study by Chen and colleagues(28).In Kolman and co-workers' study(7), inability to walk or understand the caregiver, being unhappy or sad, and not going to school were significant predictors of their poor QOL in children with CP.

The results of this study also demonstrated a significant relationship between the functioning aspects of CPQOL and children's manual ability. The results of this study are different from Shelly and colleagues' (12) that showed a significant relationship between all CPQOL subscales (except "access to health services" subscale). In their study, the relationship between the physical subscales of CPQOL was stronger than the psychosocial one.Teuscherco- 
workers(2019)reported that manual ability and QOLwere associated with health in a five-year follow-up studyof children with CP. However, despite the significant relationship between children's function and physical subscale of QOL, this relationship was not significant with other subscales(29). Itmaybe concluded that a child with CP with poor performance has the potential to report a high QOL. What has been mentioned in studies as a reason for this is that the person with $\mathrm{CP}$ has the ability to adapt to the conditions of disability. This needs more evidence for elaboration.

\section{Limitations}

Due to the lack of a proper registry system for recording information on children with $\mathrm{CP}$, access to these children through randomization was not possible. Therefore, this study applied the convenient sampling procedure. One of the strengths of our study was our large sample size with appropriate distribution in various levels of gross motor function and manual ability.

\section{Declarations}

\section{Ethics approval and consent to participate}

This study was approved by the Ethical Committee of the University of Social Welfare and Rehabilitation Sciences (ID: 801/4/88/58). Informed written consent was obtained from participant parent. All methods were carried out in accordance with relevant guidelines and regulations under Ethics approval and consent to participate

\section{Consent for publication}

Not applicable

\section{Availability of data and materials}

The datasets used and/or analysed during the current study available from the corresponding author on reasonable request.

\section{Competing interests}

The authors have no conflicts of interest.

\section{Funding}

This study was supported by grant in University of Social Welfare \& Rehabilitation Science.

\section{Authors' contributions}

Mehdi Rassafiani (carried out the design and coordinated the study, participated in most of the experiments and prepared the manuscript)

Zahra Nobakht (provided assistance for all experiments and prepared the manuscript).

FarinSoleimani (carried out the design and coordinated the study, participated in most of the experiments and prepared the manuscript).

Nazila Akbar Fahimi (provided assistance for all experiments).

RoshanakVameghi (provide assistance in the design of the study, coordinated and carried out all the experiments and participated in manuscript preparation)

\section{Acknowledgments}

The authors express their sincere thanks to Valiasr Rehabilitation Institute managers, the Association for the Support of Children and Adolescents with Disabilities, and the parents of children with cerebral palsy who provided their support during data collection. This article is the result of a research project funded by the Pediatric Neurorehabilitation Research Center of the University of Social Welfare and Rehabilitation Sciences.

\section{References}

1. Rosenbaum P, Paneth N, Leviton A, Goldstein M, Bax M, Damiano D, et al. A report: the definition and classification of cerebral palsy April 2006. Developmental Medicine \& Child Neurology. 2007;109(suppl 109):8-14.

2. Rassafiani M, Sahaf R. Hypertonicity in children with cerebral palsy: a new perspective. Iranian Rehabilitation Journal 2011;11(14):66-74.

3. Cans C, De-la-Cruz J, Mermet MA. Epidemiology of cerebral palsy. Paediatrics and Child Health. 2008;18(9):393-8.

4. Soleimani F, Vameghi R, Rassafiani M, Akbarfahmi N, Nobakht Z. Cerebral palsy: motor types, gross motor function and associated disorders. Iranian Rehabilitation Journal. 2011;11(14):21-31.

5. Waters E, Maher E, Salmon L. Development of a condition-specific quality of life scale for children with cerebral palsy: empirical data reported by parents and children. Child: Care, Health and Development. 2005;31:127-35.

6. ICF-CY W. International classification of functioning, disability and healthy, children \& youth version. Geneva: World Health Organization. 2007.

7. Kolman SE, Glanzman AM, Prosser L, Spiegel DA, Baldwin KD. Factors that predict overall health and quality of life in non-ambulatory individuals with cerebral palsy. The lowa Orthopaedic Journal. 2018;38:147. 
8. Kobayashi K, Kamibeppu K. Measuring quality of life in Japanese children: Development of the Japanese version of PedsQL. Pediatrics International. 2010;52(1):80-8.

9. World Health Organization. Measuring quality of life: The World Health Organization quality of life instruments (the WHOQOL-100 and the WHOQOLBREF). Retirado de http://www. who. com em; 2009.

10. Davis E, Waters E, Mackinnon A, Reddihough D, Graham HK, Mehmet-Radji O, et al. Paediatric quality of life instruments: a review of the impact of the conceptual framework on outcomes. Developmental Medicine \& Child Neurology. 2006;48(4):311-8.

11. Mann K, Tsao E, Bjornson KF. Physical activity and walking performance: influence on quality of life in ambulatory children with cerebral palsy (CP). Journal of Pediatric Rehabilitation Medicine. 2016;9(4):279-86.

12. Shelly A, Davis E, Waters E, Mackinnon A, Reddihough D, Boyd R, et al. The relationship between quality of life and functioning for children with cerebral palsy. Developmental Medicine \& Child Neurology. 2008;50(3):199-203.

13. Park E-Y. Path analysis of strength, spasticity, gross motor function, and health-related quality of life in children with spastic cerebral palsy. Health and Quality of Life Outcomes. 2018;16(1):1-7.

14. Maher CA, Toohey M, Ferguson M. Physical activity predicts quality of life and happiness in children and adolescents with cerebral palsy. Disability and Rehabilitation. 2016;38(9):865-9.

15. Power R, King C, Muhit M, Heanoy E, Galea C, Jones C, et al. Health-related quality of life of children and adolescents with cerebral palsy in low-and middle-income countries: a systematic review. Developmental Medicine \& Child Neurology. 2018;60(5):469-79.

16. Cans C. Surveillance of cerebral palsy in Europe: a collaboration of cerebral palsy surveys and registers. Developmental Medicine \& Child Neurology. 2000;42(12):816-24.

17. Waters E, Davis E, Boyd R, Reddihough D, Mackinnon A, Graham H. Cerebral palsy quality of life questionnaire for children (CP QOL-Child) Manual. 2006.

18. Waters E, Davis E, Mackinnon A, Boyd R, Graham HK, Lo SK, et al. Psychometric properties of the quality of life questionnaire for children with CP. Developmental Medicine and Child Neurology. 2007;49(1):49-55.

19. Soleimani F, Vameghi R, Kazemnejad A, Fahimi NA, Nobakht Z, Rassafiani M. Psychometric properties of the persian version of cerebral palsy quality of life questionnaire for children. Iranian Journal of Child Neurology. 2015;9(1):76-86.

20. Palisano RJ, Rosenbaum P, Bartlett D, Livingston MH. Content validity of the expanded and revised Gross Motor Function Classification System. Developmental Medicine \& Child Neurology. 2008;50(10):744-50.

21. Riahi A, Rassafiani M, Binesh M. The cross-cultural validation and test-retest and inter-rater reliability of the Persian translation of parent version of the Gross Motor Function Classification System for children with Cerebral Palsy. Archives of Rehabilitation. 2013;13:25-30.

22. Eliasson AC, Krumlinde-Sundholm L, Rösblad B, Beckung E, Arner M, Öhrvall AM, et al. The Manual Ability Classification System (MACS) for children with cerebral palsy: scale development and evidence of validity and reliability. Developmental Medicine \& Child Neurology. 2006;48(7):549-54.

23. Riyahi A, Rassafiani M, AkbarFahimi N, Sahaf R, Yazdani F. Cross-cultural validation of the Persian version of the Manual Ability Classification System for children with cerebral palsy. International Journal of Therapy and Rehabilitation. 2013;20(1):19-24.

24. Gunel MK, Mutlu A, Tarsuslu T, Livanelioglu A. Relationship among the Manual Ability Classification System (MACS), the Gross Motor Function Classification System (GMFCS), and the functional status (WeeFIM) in children with spastic cerebral palsy. European Journal of Pediatrics. 2009;168(4):477-85.

25. Vargus-Adams J. Health-related quality of life in childhood cerebral palsy. Archives of Physical Medicine and Rehabilitation. 2005;86(5):940-5.

26. Wake M, Salmon BA, Reddihough D. Health status of Australian children with mild to severe cerebral palsy: cross-sectional survey using the Child Health Questionnaire. Developmental Medicine \& Child Neurology. 2003;45(3):194-9.

27. Omura J, Fuentes M, Bjornson K. Participation in daily life: influence on quality of life in ambulatory children with cerebral palsy. PM\&R. 2018;10(11):1185-91.

28. Chen C-M, Chen C-Y, Wu KP, Chen C-L, Hsu H-C, Lo S-K. Motor factors associated with health-related quality-of-life in ambulatory children with cerebral palsy. American Journal of Physical Medicine \& Rehabilitation. 2011;90(11):940-7.

29. Caspar-Teuscher M, Studer M, Regényi M, Steinlin M, Grunt S, Bigi S, et al. Health related quality of life and manual ability 5 years after neonatal ischemic stroke. European Journal of Paediatric Neurology. 2019;23(5):716-22. 